\title{
CULTURA AUTORITÁRIA, ULTRACONSERVADORISMO, FUNDAMENTALISMO RELIGIOSO E O CONTROLE IDEOLÓGICO DA EDUCAÇÃO BÁSICA PÚBLICA1.
}

\author{
Gaudêncio Frigotto \\ Sonia Maria Ferreira ${ }^{3}$
}

\section{Resumo}

Este artigo busca analisar as determinações histórico-culturais que impedem que a maioria dos jovens brasileiros tenha o direito social e subjetivo do Ensino Médio. No primeiro ponto, situamos o que Karel Kosik denominou de "metafísica da cultura" para designar a concepção da realidade social como soma de fatores e não como uma estrutura de relações sociais de poder. Essa visão ahistórica, do liberalismo conservador nascente transforma-se em ultraconservadora no contexto da crise estrutural do capital. Na sequência, buscamos analisar a cultura autoritária e ultraconservadora na especificidade de nossa formação social e que, no presente, conjuga-se com o fundamentalismo religioso.

Palavras-chave: Cultura autoritária. Ultraconservadorismo. Fundamentalismo. Controle ideológico.

\section{AUTHORITY CULTURE, ULTRACONSERVADORISM, RELIGIOUS FUNDAMENTALISM AND THE IDEOLOGICAL CONTROL OF PUBLIC BASIC EDUCATION.}

\section{Abstract}

This article aims at analyzing the historical-cultural determinations, as much as legal, political and economic, which thwarts the majority of young Brazilians, in consecutive generations, from guaranteeing their social and subjective right to middle school. Initially, we situate what Karel Kosik denominated as "metaphysics of culture" to designate the bourgeois conception of social reality as a sum of factors and not as a structure of social relations of power. This ahistorical, racionalist and empiricist perspective of emerging conservative liberalism becomes ultraconservative in the context of the structural capitalist crisis. Following up, we seek to analyze the authoritarian and ultraconservative culture in the uniqueness of our social formation, which is conjugated with religious fundamentalism in our contemporary period.

Keywords: Authoritarian Culture. Ultraconservatism. Fundamentalism. Ideological control.

\footnotetext{
${ }^{1}$ DOI: https://doi.org/10.22409/tn.17i32.p28304

${ }^{2}$ Graduado em Filosofia e Pedagogia. Mestre e Doutor em Educação. Professor titular em Economia Política da Educação, na Universidade Federal Fluminense (aposentado) e, atualmente, professor no Programa de Pós-Graduação em Políticas Públicas e Formação Humana, da Universidade do Estado do Rio de Janeiro.

${ }^{3}$ Doutora em Políticas Públicas e Formação Humana, pela Universidade do Estado do Rio de Janeiro. Realiza pós-doutorado sob o título Traços históricos do autoritarismo no Brasil: uma visão a partir do elemento cultural, na Universidade do Estado do Rio de Janeiro.
} 


\section{CULTURA AUTORITARIA, ULTRACONSERVADORISMO, FUNDAMENTALISMO RELIGIOSO Y EL CONTROL IDEOLÓGICO DE LA EDUCACIÓN BÁSICA PÚBLICA.}

\section{Resumen}

Este artículo busca analizar las determinaciones histórico-culturales que impiden que la mayoría de los jóvenes brasileños tenga el derecho social y subjetivo a la Enseñanza Media. En el primer punto, situamos lo que Karel Kosik denominó de "metafísica de la cultura" para designar la concepción de la realidad social como suma de factores y no como una estructura de relaciones sociales de poder. Esa visión a-histórica del liberalismo conservador naciente se transforma en ultraconservadora en el contexto de la crisis estructural del capital. En secuencia, buscamos analizar la cultura autoritaria y ultraconservadora en la especificidad de nuestra formación social y que, en el presente, se conjuga con el fundamentalismo religioso.

Palabras-clave: Cultura autoritaria. Ultraconservadorismo. Fundamentalismo. Control ideológico.

\section{Introdução}

O contexto político dentro do qual se efetiva o IV Intercâmbio Nacional de Pesquisa em Trabalho e Educação (INTERCRíTICA) nos interpela a um balanço que extrapola este evento e que demanda uma agenda de médio prazo sobre nossas análises que tomam por base o materialismo histórico dialético. Interpelação esta que, ao contrário de sua negação, incide na questão sobre a saturação de suas categorias no âmbito de nosso tempo e na particularidade de nossa sociedade.

Estamos dentro de um clima em que o autoritarismo, o ultraconservadorismo econômico ${ }^{3}$ e o fundamentalismo religioso assumem feições neofacistas em escala ampliada em relação ao que se manifestou nos movimentos de 2014-2015 e que orquestraram o Golpe de Estado de agosto de 2016. Escrevemos este texto um dia após a definição das eleições em que, como afirma o sociólogo Roberto Dutra: "trata-se da maior vitória eleitoral da direita na história política brasileira. E não se trata de qualquer direita, mas de uma direita extremada (grifos do autor), militarizada e autoritária em todas as esferas da sociedade, na Igreja, na escola, no partido, em tudo"”.

\footnotetext{
${ }^{3}$ Ao longo do texto utilizaremos o termo ultraconservador ou ultraconservadorismo no plano econômico e social para expressar uma fase que radicaliza o que a literatura denominou de neoliberalismo. Fase esta que vai além das teses do ajuste das economias periféricas à custa de direitos da classe trabalhadora. Trata-se, agora, de ajuste com austeridade. O caso brasileiro, pósgolpe de Estado de 2016, em suas contrarreformas, expressa esse ultraconservadorismo de forma extrema. Com a eleição de forças sociais de extrema direita, o que se anuncia é uma radicalização. $O$ futuro Ministro da Fazenda anuncia o projeto de privatizar tudo. E o anúncio da carteira de trabalho verde e amarela coloca o dilema cínico: os direitos ou o trabalho?

${ }^{4}$ Disponível em: http://www.ihu.unisinos.br/584206-a-maior-vitoria-da-direita-na-historia-politicabrasileira-entrevista-especial-com-roberto-dutra. Acesso em: 30 out. 2018.
} 
O que se anuncia em termos de ministeriáveis confirma a análise de Dutra. No Ministério da Educação, os nomes que circulam são os protagonistas do Movimento Escola Sem Partido ou pessoas afinadas com esta ideologia, que se autodenominam sem partido e sem ideologia. No Ministério da Justiça, já confirmado o ministro Sérgio Moro, nacional e internacionalmente interpelado por suas decisões, e que por esta razão está sendo questionada sua indicação no Conselho Nacional de Justiça.

Listas de autores para não serem lidos já circulam há mais tempo. De igual modo, agora se confirma, em pronunciamento do recém-eleito presidente da República, aquilo que o Movimento Escola Sem Partido postula: a eliminação nas escolas do pensamento da obra de Paulo Freire. Mas o que de demoníaco, revolucionário e perigoso teria a obra deste professor se o seu livro mais importante, Pedagogia do oprimido, está publicado em dezenas de idiomas?

Seria pelo simples fato que expõe um método de alfabetização de adultos que os reconhece como sujeitos detentores de saberes, valores e cultura e ponto de partida para avançar no conhecimento sistematizado que os faculte a uma leitura autônoma e consciente da sociedade em que vivem? Ou seria, talvez, ignorância sobre sua obra?

Estamos, pois, numa encruzilhada sem precedentes em nossa história, que tem que ser lida na gravidade de suas possíveis consequências. Nos termos de Walter Benjamin, trata-se de nos dispormos a perceber que "a história deve ser escovada a contrapelo" (BENJAMIN, apud LÖWY, 2011, p. 2). Este escovar a contrapelo implica levar a sério o que nos alerta o historiador e educador norteamericano Mark Bray:

O combate ao fascismo hoje começa pela capacidade de reconhecêlo para além dos lugares-comuns, como ensina a dura experiência da Europa no período entre as duas guerras mundiais (...). O fascismo e o nazismo emergiram como clamores emocionais, antirracionais, fundados em promessas másculas de renovação do vigor nacional. (BRAY, 2018, p. 1).

No processo de escovar a nossa história a contrapelo, os lugares menos comuns a que se refere Mark Bray, certamente, encontram-se, como veremos adiante, na cultura colonizada e colonizadora e escravocrata marcante desde o descobrimento do Brasil. Este é o eixo central de pesquisa que estamos 
desenvolvendo e que busca analisar as determinações de ordem histórico-culturais e de caráter legal, político e econômico que impedem que a maioria dos jovens brasileiros, em sucessivas gerações, garanta o direito social e subjetivo do Ensino Médio e, para os que o frequentam, o façam dentro de uma concepção dual, fragmentária e economicista e em condições materiais objetivas que impedem sua efetiva qualidade.

O percurso que efetivamos até o presente nos conduz a perceber que, desde nossa gênese como sociedade colonizada e colonizadora e de quase quatro séculos de regime escravocrata, herdamos o conservadorismo e o autoritarismo como traços culturais permanentes e que, com o aprofundamento da crise estrutural universal, global e contínua do sistema capitalista, assumem traços de fascismo societário. Traços estes que, em nossa particularidade de sociedade de capitalismo tardio ${ }^{5} \mathrm{e}$ dependente, sustentam um aparato político jurídico que garante uma descomunal concentração da propriedade privada dos meios e instrumentos de produção e da riqueza a velhas e novas oligarquias.

Compreender o que nos trouxe até aqui no interior das relações sociais capitalistas, e estas na especificidade de nossa sociedade, implica desvelar as mediações que, no final do século $X X$ e início do século $X X I$, o conservadorismo liberal transformou-se em ultraconservadorismo que conjumina fundamentalismo econômico, autoritarismo e fundamentalismo religioso. Por essa via, também

\footnotetext{
${ }^{5} \mathrm{O}$ capitalismo tardio é entendido aqui em dois sentidos, mas que se potenciam para compreender nossa estrutura social despótica, autoritária e profundamente desigual. No primeiro sentido se refere a nações como o Brasil, que tiveram longos períodos de colonização e escravidão e que só tardiamente efetivaram a revolução burguesa e com características específicas. No caso brasileiro, como mostra, entre outros pesquisadores, Florestan Fernandes $(1974 ; 1975)$, constitui-se uma burguesia que não efetivou a revolução burguesa no padrão clássico, mas um capitalismo dependente de desenvolvimento desigual e combinado. O conceito de desenvolvimento desigual e combinado foi formulado originariamente por Ernest Mandel (1972). Este designa estruturas sociais que combinam nichos de desenvolvimento com alta concentração de propriedade e riqueza e manutenção e ampliação da pobreza e miséria. Também é de Mandel a formulação inicial de capitalismo tardio num segundo sentido. Partindo da herança teórica de Marx sobre a crise no sistema capitalista, crise fundamentalmente de reprodução ampliada do capital, Mandel sustenta a inviabilidade do atual padrão de produção e de consumo em face do esgotamento dos recursos naturais. E como mostram as análises contemporâneas de István Mészáros (2000), David Harvey (2011; 2018) e Elmar Altvater (2010) trata-se de um capitalismo de produção destrutiva que, ao dizimar as bases da vida (natureza e trabalho), dizima junto o acúmulo de direitos econômicos, sociais e subjetivos, alcançados pela humanidade com lutas e sacrifício de vidas.
} 
desvelar as raízes e suas permanências na forma de autoritarismo, ultraconservadorismo e fundamentalismo religioso e controle ideológico da escola pública.

\section{A gênese e a crise estrutural do capitalismo: ultraconservadorismo, autoritarismo e meritocracia.}

Diferentes perspectivas teóricas nos mostram que a afirmação do modo de produção capitalista nas suas relações sociais de produção implicou uma ruptura civilizatória com o Estado absolutista, com o regime escravocrata e com a hegemonia do pensamento metafísico da Igreja Católica. Mas, concomitantemente, para manter a nova estrutura social instaurou-se o que o filósofo Karel Kosik (1986) denominou de metafísica da razão e da cultura, vale dizer, do pensamento individualista, racionalista e meritocrático do liberalismo conservador.

Dos teóricos do liberalismo conservador — John Locke (1632-1704), David Hume (1711-1776), Adam Smith (1723-1790) e John Stuart Mill (1806-1877) —, aos que depois de um período de liberalismo social retomam o neoconservadorismo em outras bases (neoliberalismo) — Friedrich Hayek (1889-1992), Ludwig von Mises (1881-1973) e Milton Friedman (1912-2006) —, o suposto que embasa as relações sociais é de uma natureza humana sem história, centrada na racionalidade individual de um ser humano que tende ao bom, ao útil, ao agradável, e que é movido pelo egoísmo e pelo bem próprio. Uma sociedade, portanto, que estaria baseada na natureza mesmo dos seres humano.

O mercado como espaço onde cidadãos juridicamente iguais e também portadores da mesma racionalidade funcionaria, na definição de Adam Smith, como uma mão invisível, harmonizando as escolhas individuais de sorte que a tendência seria sempre o equilíbrio. Ideia esta retirada do pensamento metafísico da providência divina. O Estado, definido como o órgão do bem comum, zelaria para corrigir possíveis anomalias ou disfunções. Uma concepção que desconsidera e mascara o processo histórico, desde o surgimento do excedente, da dominação de grupos e classes sobre outros grupos e classes.

Ao igualar liberdade formal de escolha às condições desiguais reais na estrutura social, toma-se a meritocracia como sendo mérito individual. Assim, a superação do escravismo, certamente um passo civilizatório, não deu ao escravo as 
mesmas condições de escolha dos que tinham acumulado capital primitivo ou capital comercial, que lhes facultou a se tornarem proprietários privados de meios e instrumentos de produção e, no mercado, compradores da força de trabalho de escravos libertos, agora duplamente livres dos seus proprietários e de propriedade.

Cabe ressaltar, todavia, que tanto no plano das relações econômicas quanto correlatamente no campo educacional, desde o início da afirmação do modo de produção capitalista, pensadores postulavam tratamento desigual entre a classe proprietária e dirigente e os trabalhadores. No plano econômico, Thomas Robert Malthus (1766-1834), estudioso da demografia e da economia, percebia a necessidade de controlar o aumento dos pobres. Do mesmo modo, Antoine Destutt de Tracy (1754-1836), em sua ampla obra Elementos de Ideologia, vai postular um sistema escolar para os filhos da classe trabalhadora diverso do da classe dominante.

Malthus propõe dois mecanismos para conter o aumento demográfico que levaria à desgraça da fome: preventivos e controles positivos. Os primeiros relacionam-se a estratégias de diminuição da natalidade para os pobres e, o segundo, seria o de facilitar o aumento de sua mortalidade. Sobre este segundo mecanismo, Malthus (1961) indica:

E se encararmos com horror a vista e por demais frequente desse terrível espectro da fome, mais uma razão para encorajarmos com diligência as outras formas de destruição, compelindo a natureza a fazer uso delas. Em nossas cidades, deveríamos construir ruas mais estreitas, apinhar mais gente no interior das casas e provocar o retorno de pragas. No campo, deveríamos construir aldeias de colonos em terrenos de água estagnada e, sobretudo, encorajar o estabelecimento de colonos e, terrenos pantanosos e insalubres. Acima de tudo, deveríamos desencorajar o uso de medicamentos específicos que anulam os efeitos devastadores das moléstias, e condenar, também, os homens benevolentes, mas profundamente equivocados, que julgam prestar grandes serviços à humanidade quando elaboram planos para extirpar determinadas moléstias. Se, por estes e outros meios semelhantes, conseguíssemos dilatar a taxa de mortalidade anual, provavelmente, qualquer um de nós poderia casar ainda na puberdade, e mesmo assim poucos morreriam de fome (grifos nossos). (MALTHUS, apud HUNT \& SHERMAN, 1987, p. 64-5).

Assim como Malthus, Destutt de Tracy reconhece a desigualdade real e a fundamenta como uma questão da natureza. Por isso que Destutt sustentava que em todo o Estado bem administrado deveriam haver dois tipos de educação, um 
para os filhos da classe dirigente e outro aos que se destinam ao duro ofício do trabalho.

Os homens da classe operária têm desde cedo a necessidade do trabalho de seus filhos. Essas crianças precisam adquirir desde cedo o conhecimento e sobretudo o hábito do trabalho penoso a que se destinam. Não podem perder tempo nas escolas (...). Os filhos da classe erudita, ao contrário, podem dedicar-se a estudar durante muito tempo; têm muitas coisas para aprender para alcançar o que se esperas deles no futuro. (...) Estes são fatos que não dependem de qualquer vontade humana; decorrem necessariamente da própria natureza dos homens e da sociedade. (DESTUTT DE TRACY, 1908 $\mathrm{s} / \mathrm{p})$.

O que Malthus e Destutt de Tracy assumem é a necessidade da desigualdade real entre as classes sociais, para que o novo modo de produção funcione dentro de sua compulsão à exploração e ao lucro $^{6}$. O processo histórico, de forma cabal e inequívoca, mostrou que o livre mercado, sob relações sociais desiguais, teve como resultado a desigualdade contínua e crescente entre nações, classes e grupos sociais. Isto levou o historiador Eric Hobsbawm (1996) a definir o século XX como uma era dos extremos, marcada por duas sangrentas guerras mundiais, uma revolução socialista na Rússia, ampliada após a Segunda Guerra Mundial, e uma crise profunda do sistema capitalista mundial.

A crise de 1929 do sistema capitalista evidenciou que o capital desregulado constitui-se uma força destrutiva sem limites e que acaba gerando riscos ao próprio sistema capitalista. É neste contexto que surgem a teoria keynesiana sobre a função do Estado no processo de regulação do capital e, ao mesmo tempo, se busca fomentar políticas sociais na reprodução da força de trabalho e sua inserção no sistema produtivo. Como observa Hobsbawm, na obra supracitada, funcionou "o Estado de Bem-Estar Social em pelo menos duas dezenas de nações" e foi o período de ouro do capitalismo.

Contraditoriamente, as estratégias para salvar o sistema capitalista redundaram, também, em ganhos para a classe trabalhadora, ainda que de forma muito desigual em diferentes nações do mundo, inclusive no Brasil, como veremos no item 2. O modelo fordista de regulação, como ficou sendo denominado pela literatura econômica e de gestão, tratou de combinar três mecanismos: a

\footnotetext{
${ }^{6}$ Para compreender que os liberais, no Plano Real, nunca o foram de fato, mas, ao contrário, eram escravistas, ver a análise densa de Domenico Losurdo no livro Contra-história do liberalismo (2009).
} 
organização e divisão específica do trabalho (taylorismo/fordismo); um regime de acumulação que combina produção e consumo em larga escala; e um estatuto jurídico ideológico, com normas, leis e instituições para regular as relações sociais, conflitos intercapitalistas e capital-trabalho.

É neste contexto que a educação escolar, o treinamento e a questão da saúde entram como políticas de reprodução da força de trabalho para o conjunto dos capitalistas e como estratégia de diminuição da desigualdade entre nações e entre grupos sociais. Não por acaso os economistas e os intelectuais coletivos do capital (Banco Mundial, Organização Mundial do Comércio, Organização Internacional do Trabalho e Banco Interamericano de Desenvolvimento) assumem, a partir já da década de 1950, estudos sobre a educação como "fator de desenvolvimento e mobilidade social".

Duas obras de Theodore Schultz explicitam a concepção de educação como um capital: O valor econômico da educação (Schultz, 1962) e Capital humano (Schultz, 1973). Uma visão ideológica que estabelece, a um tempo, a educação não como direito social e subjetivo, mas como um serviço mercantil e uma visão circular a qual não explica por que os países e indivíduos pobres têm menos investimento e graus de escolaridade?

O sistema capital, para operar em sua natureza de buscar o lucro máximo e voltar à sua irracionalidade, tem como prerrogativa desvencilhar-se de regulações e confrontar e, se possível for anular o poder da classe trabalhadora. $E$ isso se deu de forma gradativa, desde a década de 1940, com a estratégia das multinacionais, na década de 1960, com empresas transnacionais, e, a partir do final da década de 1970, com a hegemonia do capital mundial na sua forma financeira e fictícia. Agora, os Estados nacionais passam a ser regulados pelo direito internacional do capital com seus organismos anteriormente citados.

Duas determinações fundamentais permitiram ao sistema capital, ao mesmo tempo, implodir as políticas regulacionistas keynesianas e as políticas do Estado de Bem-Estar Social: vingar-se dos ganhos da classe trabalhadora e instaurar estratégias ultraconservadoras e autoritárias para enfrentar sua crise estrutural, universal, global e contínua. A apropriação privada deu um salto de tecnologia não

\footnotetext{
${ }^{7}$ Para uma análise crítica da teoria do capital humano e seus reducionismos, ver FRIGOTTO (1984).
} 
mais rígida, mais flexível (digital-molecular), que associa microeletrônica e informação e o colapso do socialismo real.

No plano político, estava dada a chave para Margaret Thatcher proclamar que não via a sociedade e sim indivíduos, senha para montar estratégias de desmontar a organização política e sindical da classe trabalhadora. $E$ isso lhe é permitido mediante o deslocamento de empresas e a substituição do trabalho vivo dos trabalhadores pelo novo salto tecnológico que permite demitir em massa, como demonstra a socióloga Danièle Linhart (2007) na obra A desmedida do capital.

A regressão ao neoconservadorismo em sua forma ultraconservadora explicitou-se no fato de que as obras, em especial a de Friedrich Hayek - $O$ caminho da servidão (1987) - e de Milton Friedman - Capitalismo e liberdade (1977) e Liberdade de escolher (1980) —, tornaram-se uma espécie de Bíblia para o receituário do ajuste nas décadas de 1980 e 1990 dos países endividados e de desregulamentação das leis trabalhistas. Receituário que no encontro conhecido como Consenso de Washington definiu as dez medidas básicas:

Disciplina fiscal. Redução dos gastos públicos. Reforma tributária. Juros de mercado. Câmbio de mercado (...) Abertura comercial. Investimento estrangeiro direto, com eliminação de restrições. Privatização das estatais. Desregulamentação (afrouxamento das leis econômicas e trabalhistas). Direito à propriedade intelectual ${ }^{8}$.

Esse conjunto de medidas não diminuiu a desigualdade, ao contrário, ampliou-a de forma exponencial ${ }^{9}$. Do mesmo modo, não supera a crise estrutural, mas esta se torna cada vez mais profunda, destrutiva e explosiva como demonstram as análises de István Mészáros (2016), David Harvey (2011; 2018), Elmar Altvater (2010), Eric Hobsbawm (2000), entre outros pensadores contemporâneos. Agora se acresce ao ajuste dos países a tese da austeridade com novas e radicais desregulamentações das leis que protegem a classe trabalhadora.

A síntese destas análises incide numa mesma direção: a irracionalidade do capital está, de forma crescente, aniquilando os dois fundamentos da reprodução da vida: a natureza, com a destruição ambiental, poluição e escassez da água, limite

\footnotetext{
${ }^{8}$ Disponível em:

https://pt.wikipedia.org/wiki/Consenso_de Washington\#A pr\%C3\%A1tica na pol\%C3\%ADtica_econ $\%$ C3\%B4mica mundial. Acesso em 24 de outubro de 2018.

${ }^{9} \mathrm{O}$ economista Thomas Piketty (2014), com o suporte de uma série histórica de dez décadas mostra que a desigualdade sistematicamente cresceu em todos os países do mundo.
} 
dos bens fósseis e aquecimento global; e a destruição ou exploração e expropriação da força de trabalho. Uma destruição que se mantém por regimes políticos cada vez mais autoritários e com práticas neofacistas. O malthusianismo no século XXI se materializa pelo assalto do capital ao fundo público e pela restrição das políticas públicas, tendo como consequência a morte decorrente da fome, o retorno de pragas, as guerras regionais, pela morte de refugiados nos mares e pelas mais diversas formas de violência contra os pobres do mundo.

\section{Reiteração da cultura autoritária, conservadorismo e fundamentalismo religioso}

O que foi apresentado de forma sintética anteriormente é da natureza das contradições insanáveis do sistema capital e a sua necessidade de utilizar-se de formas cada vez mais autoritárias, regressivas e destrutivas da vida humana para manter-se. Todavia, isto assume um caráter mais devastador na sociedade brasileira de capitalismo tardio e dependente em decorrência de sua forma de colonização e de quase quatro séculos de escravidão. Nos âmbitos econômico, jurídico e político, estas raízes plasmam uma cultura autoritária e conservadora que se reproduz e se potencia ao longo de nossa formação histórica e, atualmente assume traços neofacistas.

Colono é aquele que cultiva a terra alheia e paga tributos ao proprietário. Colonizado é aquele que é submetido a um processo de assumir a cultura e a visão de mundo dos colonizadores. O escravo na modernidade é concebido como meio de produção, coisa e animal que fala. Os colonizadores trouxeram consigo suas visões de mundo, seus deuses e seus modelos educativos. Num tempo histórico em que dominava a visão metafísica do mundo e onde a Igreja Católica era detentora de poder dos "céus e da terra", os povos originários foram concebidos como selvagens ímpios e, portanto, sem alma. Os escravos, seres não civilizados e cultuando deuses estranhos. Portanto, suas crenças, seus deuses, seus saberes e valores não tinham legitimidade. A tarefa era convertê-los a qualquer preço, vale dizer, colonizá-los e, em grande medida, dizimá-los.

(...) a dominação essencial de determinada classe na sociedade mantém-se não somente, ainda que certamente se for necessário, pelo poder, e não apenas, ainda que sempre pela propriedade. Ela 
se mantém também inevitavelmente pela cultura do vivido: aquela saturação do hábito, da experiência, dos modos de ver, que é continuamente renovada em todas as etapas da vida, desde a infância, sob pressões definidas e no interior de significados definidos. (WILLIAMS, 2007, p. 14).

A cultura do vivido, que cimenta e reitera ao longo do tempo o autoritarismo, o conservadorismo, o moralismo e o preconceito dos povos originários (índios), dos negros e, mais tarde, dos pobres, tem suas raízes entre nós, como demonstra Juremir Machado da Silva, sobre o regime escravocrata. Os defensores dos donos dos escravos viam na escravidão um bem para a civilização. Muitos de nós lemos José de Alencar em seus romances, mas não o lemos, talvez, em seus pronunciamentos, como deputado ultraconservador na defesa da propriedade das fazendas e dos escravos e que era contra a abolição. Por um lado, a escravidão, o tráfico era benéfico à civilização. Por outro, acusava os abolicionistas de serem os veiculadores do socialismo e do comunismo, isso na década de 1867, onze anos antes da abolição.

Eis um dos benefícios do tráfico. Cumpre não esquecer, quando se trata desta questão importante, que a raça branca, embora reduzisse o africano à condição de uma mercadoria nobilitou-o não só pelo contato, como pela transfusão do homem civilizado. A futura civilização da África está aí neste fato em embrião. (ALENCAR, apud DA SILVA, 2018, p. 61).

Percebendo tendências abolicionistas nos quadros de poder da monarquia, Alencar advertia sobre o que, com a abolição, poderia ocorrer:

Tolerado semelhante fanatismo do progresso, nenhum princípio social fica isento de ser ele atacado mortalmente ferido. A mesma monarquia, senhor, pode ser varrida para o canto entre o cisco das ideias estritas e obsoletas. A liberdade e a propriedade, essas duas fibras sociais, caíram desde já em desprezo ante os sonhos do comunismo (grifos nossos). (ibid, p. 57).

Vale ressaltar que, 140 anos depois desta argumentação de Alencar, a defesa da liberdade e da propriedade é o foco permanente a defender e o que ameaça são os sonhos do comunismo. Esta continuidade, impregnada na cultura e reiterada pelos diferentes aparelhos de hegemonia, é acionada toda vez que as lutas sociais buscam alterar uma das mais perversas estruturas sociais de desigualdade mundial. A síntese de Luis Fernando Verissimo capta esta continuidade. "Está no DNA da 
classe dominante brasileira, que historicamente derruba, pelas armas se for preciso, toda a ameaça ao seu domínio, seja qual for sua sigla ${ }^{10 . "}$

Duas passagens da obra Raízes do conservadorismo, de Juremir Machado, expõem como a classe dominante brasileira incorpora mudanças na lei, mas não rompe a defesa de seus interesses e com as formas de dominação e exploração para mantê-los ${ }^{11}$.

A abolição da escravidão inaugurou simultaneamente o longo ciclo de marginalização do negro. Uma marginalização nova, em relação ao que acabava de extirpar, a marginalização do homem livre como suspeito por antecipação de crimes que poderia ou não cometer. $\mathrm{O}$ crime maior seria o de ser negro. (ibid. p. 25).

A reiteração da continuidade das novas formas de escravidão dos libertos sintetiza-se na conclusão do livro de Da Silva: $A$ história não para de exumar cadáveres. Não há mais trégua para a infâmia. $O$ ano esquecido, 1888, é um espectro que ronda (ibid. p. 436). Espectro que ressurge 140 anos depois e que se espelha nas cadeias, nos crimes de estado contra os negros e pobres e se alastra para a desregulamentação das relações de trabalho. A contrarreforma trabalhista (Lei no 13.467/1917) expressa uma regressão social aos padrões escravocratas do século XIX, agora estendidos ao conjunto da classe trabalhadora. As forças sociais vitoriosas na eleição de 2018, com sua face política autoritária conjugada à defesa do ultraconservadorismo econômico, tenderão impor uma exploração e expropriação consentidas para a classe trabalhadora.

A proposta no plano de governo do presidente eleito em outubro de 2018 de criar a carteira de trabalho "verde e amarela" expressa a liquidação total da Consolidação das Leis do Trabalho (CLT), sancionada pelo Decreto Lei no 5.452 de 1ㅇ de maio de 1943. Esse processo iniciou-se em 1966, logo nos primeiros anos da ditadura empresarial militar de 1966, com a proposta da criação do Fundo de

\footnotetext{
${ }^{10}$ Disponível em: http://oglobo.globo.com/opiniao/odio-16546533\#ixzz3eAZnOCwa. Acesso em: 1 nov. 2018.

${ }^{11}$ Ver a esse respeito o mecanismo de burla das Constituições, desde o Império, em texto de Fabio Konder Comparato. Este jurista mostra a reiteração de inclusão nas Constituições das demandas populares - texto oficial - e sua burla pelo que ele denomina de Constituição subliminar. Fabio, Konder Comparato, Duas Constituições concomitantes, a democracia incompleta. Disponível em: http://www.ihuonline.unisinos.br/artigo/7223-num-brasil-de-duas-constituicoes-concomitantes-ademocracia-e-incompleta. Acesso em: 1 nov. 2018.
} 
Garantia (Projeto de Lei no 10/1966) em substituição à estabilidade no emprego, depois de dez anos atuando numa mesma empresa.

Este desmonte continuou na década de 1990, mas dada à resistência organizada na sociedade não conseguiram efetivar o que se faz dentro do golpe de Estado com a contrarreforma em vigor desde 2017. Esta mantém a atual carteira que ainda assegura o Fundo de Garantia e o INSS. Com a carteira "verde e amarela" proposta, mesmo que repita o que se disse em relação à opção pela estabilidade ou Fundo de Garantia, na verdade não há opção. Nenhum empregador vai querer manter a antiga carteira e, por isso, a opção é entre o emprego sem direitos ou o desemprego.

O ideário de imposição de escravidão consentida é proclamado pelo economista ultraconservador Gustavo Franco, ligado ao Partido Novo, mas que festeja a eleição de Bolsonaro, ao afirmar que a nova composição do Congresso não fará apenas "mudancinhas", e sim o que os empresários de fato precisam. E justifica que estes são "quem realmente produz algo neste país"12. Franco, ao dizer que quem de fato produz são os empresários, verbalizou que o trabalhador volta a ser considerado coisa, meio de produção como eram os escravos.

$\mathrm{Na}$ cultura do vivido, ao longo de nossa história, sedimenta-se o discurso da ameaça do socialismo e comunismo à liberdade e à propriedade, mas também, como sinalizamos anteriormente, à moral, à religião e aos valores da família. $\mathrm{A}$ imposição da religião aos selvagens e aos escravos assume novas determinações. Embora na forma da lei nos constituíssemos um estado laico, o que tem sido dominante desde o século XX é a reiteração do uso do conservadorismo religioso, mantendo os mesmos argumentos do perigo do comunismo para a nação, propriedade, liberdade e para a família.

Entretanto, no Brasil, especialmente nas últimas quatro décadas e de forma crescente, amplia-se um fundamentalismo religioso que vai além do moralismo conservador de amplos setores da Igreja Católica e de outras igrejas com fundamentos de doutrina teológica. Trata-se da expansão de diferentes denominações religiosas neopentecostais que usam Deus e a fé simples para explorar aqueles que a estrutura social mantém na pobreza e lhe nega a educação

\footnotetext{
${ }^{12} \mathrm{https}$ ://economia.uol.com.br/noticias/redacao/2018/11/01/gustavo-franco-empresarioscongresso.htm. Acesso em: 05.Fev. 2019.
} 
básica. São os modernos vendilhões dos templos que, sob as categorias de exorcismo e ideologia (teologia) da prosperidade e milagre, tiram especialmente das populações pobres para construir fortunas econômicas. Como traduziu no seu tempo Leonel Brizola (2000)13: "Estes pastores querem estação de rádio e dinheiro. São adoradores dos bezerros de ouro."

O ideário pautado no processo da eleição de Bolsonaro, afirmado tão logo eleito, explicita de forma emblemática a junção de autoritarismo, ultraconservadorismo econômico e fundamentalismo religioso. Três sinalizações reforçam estas junções: os livros sobre a mesa, mostrados na primeira mensagem via internet; a reza do pastor neste mesmo ato; e, posteriormente, a declaração num canal de TV de propriedade de grupo religioso ao lado de um pastor que é símbolo do fundamentalismo. A história nos mostra que os resultados da junção destes dois fundamentalismos têm sido trágicos. O primeiro fundamentalismo, em nome da pátria, da raça, da propriedade cometeu e comete extermínios de povos e, o segundo, em nome de crenças, instaurou a inquisição e eliminação de hereges.

O que Raymond Williams sublinha é que a dominação de classe se dá pelo poder, se preciso, e pela propriedade, sempre, mas também pela saturação da cultura do vivido em nosso processo histórico se assenta sob as marcas do autoritarismo, do liberalismo conservador ou ultraconservador, do conservadorismo ou fundamentalismo religioso. É sob a relação desta base cultural que a burguesia brasileira forjou uma sociedade de capitalismo dependente. Uma negação permanente a um projeto econômico social autônomo e, do mesmo modo e como decorrência, de termos uma cultura, ciência e educação autônomas. Como nos indica Florestan Fernandes:

O que está em jogo é antes o estabelecimento de limites e explicar porque uma ordem social burguesa, na periferia do mundo capitalista, enfrenta na esfera cultural as mesmas impossibilidades que se concretizam na esfera econômica. A dominação imperialista não deixa claros. Ao fechar o tempo histórico no plano da economia, ela também fecha o tempo histórico no plano da cultural. (FERNANDES, 1977, p. 230).

Ao renunciar à construção de um projeto de nação autônomo, a burguesia brasileira sempre abriu mão do investimento qualitativo e quantitativo na ciência

\footnotetext{
${ }^{13}$ Ver esta afirmação de Leonel Brizola na Revista Veja, edição 1663, de 23/8/2000.
} 
básica de marca original. Optou pela cópia ou compra. Consequentemente, não só não precisou, mas sempre se opôs à universalização da Educação Básica. Isso explica o fato de que, de acordo com a Pesquisa Nacional por Amostra de Domicílios Contínua (Penad) de 2016, entre os adultos, cerca de 12 milhões continuem analfabetos; entre os adultos com 25 anos ou mais, $66,3 \%$; ou $51 \%$ da população adulta tinha apenas o Ensino Fundamental. Nesta faixa etária, apenas 15\% têm nível superior. Em 2017, a taxa de escolarização das pessoas de 15 a 17 anos era de $68,4 \%$. Destes jovens, cerca de 1,3 milhão de adolescentes nessa faixa etária está fora da escola, enquanto outros 2 milhões estão atrasados ${ }^{14}$.

Mas ao examinarmos o tipo de formação escolar oferecida à maioria dos jovens brasileiros constatamos que o que predomina ao longo da nossa história é a escola dual e, cada vez mais, a diferenciação na dualidade para a maioria dos jovens brasileiros que frequenta as escolas públicas ${ }^{15}$. O que se consolida é uma reiterada continuidade na negação ao conhecimento e cultura socialmente produzidos à classe trabalhadora. O que defendia Destutt de Tracy, no final do século XVIII, sobre uma escola restrita, prática e rápida para os que se destinavam ao duro ofício do trabalho e uma ampla e demorada para quem se destinava dirigir à sociedade tem sido uma opção até o presente em nossa história. Os avanços na construção democrática, no âmbito econômico e educacional alcançados pela luta das organizações e movimentos sociais da classe trabalhadora e seus intelectuais, sistematicamente, foram truncados por ditaduras e golpes institucionais.

A partir do Golpe de Estado de 2016, com a Emenda Constitucional oo 95/2016, a contrarreforma trabalhista (Lei № 13.467/1917), a contrarreforma do Ensino Médio (Lei no 13.415/2017) e o projeto de contrarreforma da Previdência, em processo de aprovação, mesmo antes da eleição de 2018, o foco é liquidar com a esfera pública, o trabalhador público, liquidar com a Educação Básica e dar ao mercado a prerrogativa de gerir as relações trabalhistas e os processos educativos, mesmo que se mantenham formalmente o nome de escola pública. Junto a essas contrarreformas, e para mantê-las, se necessário pela força, tramitam a lei antiterror,

\footnotetext{
${ }^{14}$ Disponível em: https://www.correio24horas.com.br/noticia/nid/apenas-684-dos -jovens-de-15-a-17anos-estao-no-ensino-medio-diz-ibge/. Acesso em: 5 nov. 2018.

${ }^{15}$ Ver a esse respeito a análise de Algebaile (2009).
} 
a luta para ampliar o direito de armas, o projeto do Movimento Escola Sem Partido, o projeto da diminuição da idade penal, a lei contra o aborto, entre outras iniciativas.

O que se desenha não é apenas a reiteração do passado, no que de mais trágico engendra: escravidão, desigualdade estrutural mantida por ditaduras e golpes e a manutenção da negação ao conhecimento histórico e socialmente produzido. Estas marcas culturais, econômicas, políticas e legais, sob nova face do autoritarismo articulado a teorias ultraconservadoras e ao fundamentalismo religioso, engendram e desenvolvem um tecido de fascismo societal.

Mal saído o resultado das urnas, esse conjunto de iniciativas parlamentares ganhou o ingrediente que sintetiza o retorno ao autoritarismo, opção pelo ultraliberalismo econômico e pelo fundamentalismo religioso. Deste modo, antes mesmo de assumir o governo, pode ver aprovada alguma dessas iniciativas parlamentares com maior teor coercitivo. É o caso da Lei Antiterror aprovada com vetos pela ex-presidente Dilma Rousseff. Com efeito, o senador Magno Malta, do núcleo básico da campanha de Bolsonaro, incluiu na pauta da Comissão de Constituição e Justiça do Senado a votação de um projeto que abre a possibilidade de ampliar ações que podem ser consideradas terrorismo, incluído movimentos sociais, ativistas etc. Neste contexto, as teses do Movimento Escola Sem Partido voltam com força ampliada para tornar-se lei.

\section{Ultraconservadorismo, fundamentalismo religioso e o controle ideológico na educação pública.}

Duas coisas são infinitas: o universo e a estupidez humana. Mas, em relação ao universo, ainda não tenho certeza absoluta. (Albert Einstein) $^{16}$.

A cultura do autoritarismo que, como vimos, tem suas raízes na colonização e no longo processo de escravidão, no contexto da crise estrutural do capitalismo e como esta se materializa em nossa sociedade de capitalismo dependente ganha novas determinações de caráter regressivo em todas as esferas da vida. Luciano Gallino (2015), sociólogo italiano, caracteriza os governos que adotam o receituário neoliberal ou ultraconservador como governos da estupidez humana. Trata-se das

\footnotetext{
${ }^{16}$. https://www.pensador.com/frase/MjQ3Mw/. Acesso em: 26 de Fev. 2019.
} 
políticas que se afirmam sob o argumento de ajustes e austeridade necessárias sem o que, o caos se instalaria — , para as quais não há sociedade, não há seres e necessidades humanas, há apenas mercado e o lucro maximizado, hoje predominantemente do capital financeiro.

A manutenção destas políticas, pela produção de desigualdade, desemprego estrutural, perda de direitos e degradação social que produzem, somente pode ser sustentada pela violência do arbítrio da lei e/ou das armas. Um contexto em que as teses políticas de extrema direita ganham terreno no mundo e se ampliam as práticas do Estado policial. Como vimos, a manutenção de nossa estrutura social com abismal desigualdade, e de um projeto de capitalismo dependente, manteve-se pela manipulação das leis pelas oligarquias ou por ditaduras e golpes.

Não tivemos, todavia, de forma explícita uma força social que buscasse implantar um projeto político de extrema direita. A perplexidade de parte da sociedade brasileira funda-se, atualmente, no fato de que começa entender o ovo de serpente ou a esfinge que nos ameaçam. Perplexidade que advém do teor das teses claramente defendidas por estas forças que se tornam agora governo. Mais espantoso, é que este ovo de serpente e esfinge tem como outro ingrediente o fundamentalismo religioso de seitas ou denominação neopentecostais que fundam igrejas-mercado explorando a miséria e a fé simples de multidões.

Esta materialidade tecida no terreno específico de nossas relações sociais tem como contrapartida a manutenção no obscurantismo da maioria da população brasileira, negando-lhe bases de conhecimento para uma análise autônoma da realidade em todas as suas dimensões. Concomitantemente, ao longo de nossa história, o combate ao pensamento divergente desenvolvido por intelectuais, pesquisadores, políticos e lideranças de movimentos sociais sempre se deu pelo jargão do risco do socialismo e comunismo. O paradoxal é que os que sustentam este jargão são os mesmos que veiculam as teses do fim da história com o colapso do socialismo real. Ou seja, a humanidade teria a prova de que o capitalismo é a forma de produção da existência que corresponde à natureza humana.

Diferentes análises, nos diversos âmbitos da ciência social, buscam decifrar, mormente a partir de 2013, o tecido social em que o ovo de serpente esboçou seu crescimento e como este crescimento assumiu celeridade. No campo da educação, o esforço tem sido de apreender a relação entre o processo de mercantilização da 
educação pública e o controle ideológico do conteúdo do conhecimento e métodos de abordá-lo. Isso se expressa pela criação de duas organizações que se denominam movimentos, mas que se constituem no que Gramsci denomina de partidos ideológicos: Movimentos Todos pela Educação e Escola sem Partido.

Em continuidade ao que um grupo de pesquisadores que têm buscado refletir, em duas recentes coletâneas ${ }^{17}$, sobre esta relação e seus desdobramentos no plano jurídico, buscamos neste item, ainda que de forma indicativa, retomar o que está subjacente no plano ontológico, no plano epistemológico que articula estes dois movimentos e os vendilhões dos templos do fundamentalismo religioso. Por esta via tentamos desvelar: o jogo ardiloso e cínico que engendra o termo partido, e o furor moralista que une o ultraconservadorismo econômico, o fundamentalismo religioso e o aprofundamento da cultura autoritária de extrema direita na sociedade brasileira.

A base ontológica que sustenta os fundamentos do liberalismo econômico e sua face atual ultraconservadora partem do suposto, como vimos no item 1, de uma natureza humana que tende ao bom, ao útil e ao agradável. Sendo um legado da natureza dado a todos, igualmente, a luta de cada um para satisfazer suas necessidades e desejos se daria em condições de igualdade. Assim, a luta egoísta de cada um seria a chave para a prosperidade social em que cada um receberia pelo que contribuiu para a sociedade, mas a tendência seria o equilíbrio. Adam Smith, fundador da economia clássica liberal, situou o mercado como locus no qual cada indivíduo racionalmente e livre faria suas escolhas e trocas ${ }^{18}$.

O caráter falso deste suposto se evidencia, por um lado, pelo fato de que no plano da ciência, o homem é um ser histórico natural. Isto significa que a natureza humana é histórica. E se somos seres históricos, nossa individualidade é social. A partir do suposto de uma natureza humana dada e invariável, sem levar em conta as relações sociais dominantes, anulam-se as formas históricas presidentes ao capitalismo sob a escravidão e o servilismo e mascara-se a exploração no presente. Esta anulação do processo histórico é a base sobre a qual se fundamenta a tese de que o que cada indivíduo consegue de riqueza, cultura etc. resulta de seu mérito e

\footnotetext{
${ }^{17}$ Ver: Frigotto (Org.), 2017; Penna; Queiroz; Frigotto (Orgs.), 2018.

${ }^{18}$ Ver a esse respeito Hunt \& Sherman (1987, p. 566), o que eles denominam de credo psicológico, político e econômico derivados desta concepção ontológica.
} 
não, no mais das vezes, da meritocracia. Esta não leva em conta em que condições os indivíduos fazem as suas escolhas.

Assim como os escravos não tinham as mesmas condições de escolha de seus donos, os trabalhadores não negociam a venda de sua força de trabalho em iguais condições dos seus compradores. Em situação mais dramática, são os milhões de subempregados e desempregados em todo mundo. Este suposto foi desmentido pelo percurso histórico do capitalismo que, ao contrário da igualdade e liberdade reais, tem como seu fundamento estrutural a desigualdade real e a liberdade formal.

O fundamentalismo religioso reforça esta concepção a-histórica e individualista do ser humano, mas sob o fundamento do criacionismo. O fundamento ontológico da burguesia e o antropocentrismo sem história, e o do fundamentalismo religioso a ontologia metafísica, esta supra-histórica. Não por acaso, Adam Smith vê no mercado uma espécie de um deus (mão invisível) que iria harmonizar os múltiplos e diversos interesses e escolhas individuais.

Sob estas concepções ontológicas desenvolve-se a matriz epistemológica positivista, racionalista e empirista que postula um conhecimento neutro e, portanto, isento de valores, de ideologias ${ }^{19}$. Trata-se de abordagens que tomam a realidade social, humana como uma coisa, um dado não resultante de relações sociais historicamente produzidas. Para esta matriz epistemológica, a compreensão dos fatos, acontecimentos, problemas econômicos, sociais, psíquico etc., é alcançada pela soma de fatores isolados, e não da relação das partes com a totalidade histórico-social que os constitui.

Karel Kosik denomina esta matriz ontológica e epistemológica, como já nos referimos, de metafísica da cultura. Ao entender a economia como um fator e não como uma estrutura de relações sociais assimétricas mascara-se como de fato os seres humanos produzem e reproduzem sua vida material, cultural, educacional socialmente.

A economia não é apenas a produção de bens materiais: é a totalidade da produção e reprodução do homem como ser humano social. A economia não é apenas a produção de bens materiais, é ao

\footnotetext{
${ }^{19}$ Para uma compreensão aprofundada desta matriz epistemológica. Ver Michael Löwy (2013, p. 81-
} 118). 
mesmo tempo produção das relações sociais dentro das quais a produção se realiza. (KOSIK, 1986, p. 173).

Isto nos indica que a miséria humana e religiosa é produzida nos indivíduos nas relações sociais. Se estas relações são de desigualdade real, não será no mercado que compradores de força de trabalho e vendedores fazem escolhas igualmente vantajosas. Do mesmo modo, não será a pregação da teologia, da prosperidade, sob a pregação do exorcismo e do milagre que tira os indivíduos da miséria humana e religiosa.

Em duas pequenas passagens, no livro a Sagrada família, Karl Marx, diz:

Se o homem é formado pelas circunstâncias, será necessário formar as circunstâncias humanamente. Se o homem é social por natureza, desenvolverá sua verdadeira natureza no seio da sociedade e somente ali, razão pela qual devemos medir o poder de sua natureza, não através do poder do indivíduo concreto, mas sim através do poder da sociedade (grifos nossos). (MARX, 2003, p. 150).

A frase que antecede o texto acima, na sociedade brasileira, reveste-se de uma atualidade extrema em relação ao como tratar a questão da violência. As teses da diminuição da idade penal e, mais brutalmente, o senso comum que se quer criar para a violência do Estado de que "bandido bom é bandido morto" exime a sociedade e este mesmo Estado de serem os agentes produtores da violência.

Se o homem não goza de liberdade em sentido materialista, quer dizer, se é livre não pela força negativa de poder evitar isso e aquilo, mas pelo poder positivo de fazer valer sua verdadeira individualidade, os crimes não deverão ser castigados no indivíduo, mas [deve-se] sim destruir as raízes antissociais do crime (grifos nossos) e dar a todos a margem social necessária para exteriorizar de um modo essencial sua vida. (ibid. p. 150).

Sob o horizonte de análise que desenvolvemos até aqui é possível desvelar porque, mesmo operando de forma independente, os autodenominados Movimentos Todos pela Educação, Escola sem Partido e o fundamentalismo religioso se relacionam e se reforçam. Nesta relação, entender por que isso só pode ser sustentado sob a exacerbação da cultura autoritária na forma legalizada de um Estado de exceção de marca policial.

Todos pela Educação e Escola sem Partido, por argumentos distintos, têm como pressuposto a neutralidade do conhecimento. Esta, no contexto do 
ultraconservadorismo econômico, pavimenta as ações do Movimento Todos pela Educação, não apenas de fazer da educação um negócio rendoso, mas, também, de orientar os conteúdos e métodos, supostamente neutros, para os conhecimentos e valores que servem ao mercado. A neutralidade, por sua vez, está na base do Movimento Escola sem Partido, no argumento da doutrinação ideológica dos professores sobre os alunos, tanto no conhecimento quanto nos valores; estes propriedade exclusiva não dos pais, tidos como "donos dos filhos" e a escola como mercado, pois regulada pelo "código do consumidor".

O fundamentalismo religioso relaciona-se com ambos pelo viés mercantil da religião, sendo que com a Escola sem Partido, também, e, especialmente, pelos valores da família, combatendo o que denominam de ideologia de gênero, não com base na ciência, mas no criacionismo. Isto fica evidente nas teses que "homem nasce homem e mulher nasce mulher" e, em consequência, a diversidade de gênero e orientação sexual são consideradas doenças ou coisa do demônio. Longas sessões de encenação de "exorcismo" ou de "milagres" e a "teologia" da prosperidade são uma espécie de marketing "sagrado" do mercado destas empresas religiosas.

A acusação da ideologização pelas ciências sociais e humanas conflui para o apoio do conjunto dos dois movimentos e do fundamentalismo religioso a suas bancadas no Congresso para o que se consubstanciou na contrarreforma do Ensino Médio, nas Bases Curriculares Nacionais e agora, já, a Educação a Distância na Educação Básica, com a aprovação das Diretrizes do Ensino Médio. Esse conjunto de mudanças atende a todas essas forças conservadoras, mediante a diluição ou simplesmente das áreas das ciências sociais e humanas, e mesmo ciências da natureza na formação da maior parte da juventude brasileira.

Para impor seus objetivos tanto o Movimento Escola sem Partido quanto o fundamentalismo religioso as suas crenças valem-se do falseamento de conceitos e manipulação da boa-fé. Ao acusar que a escola tem partido, busca-se confundir os pais e a sociedade de modo geral, pois grande parte dos professores vale-se de seu público cativo para doutrinar de acordo com o partido de preferência. Se isso fosse verdade, até que seria uma doutrinação democrática, pois no conjunto dos professores há adeptos de todos os partidos políticos. Mas os proponentes do movimento sabem muito bem que não é isso. 
O que eles pretendem é que o professor se constitua um tipo de robô ou máquina neutra. Que ensine o que está programado e prescrito e de preferência por um dos dezoito institutos apoiadores do Movimento Todos pela Educação que vendem pacotes de ensino. Todas as mudanças anteriormente assinaladas na Educação Básica concorrem para esta direção. Chega-se, assim, a submeter o trabalho docente na escola pública aos padrões das prescrições da gerência científica do setor privado.

O Movimento também sabe que nenhuma escola defende um determinado partido político. O que o preocupa é sob que bases teóricas os professores efetivam sua docência em toda e qualquer área de conhecimento. Sabe que pelo conteúdo e método de produção e socialização do conhecimento trabalhado na escola, ela exerce uma determinada função política: transformadora ou conservadora. O que o preocupa e autoritariamente querem silenciar são aquelas análises que têm sua base em autores que ajudam aos jovens a entender a natureza das relações sociais de classe, sob uma sociedade das mais desiguais e violentas do mundo. Ou seja, autores e análises que dão base para que cada um, autonomamente, exerça aquilo que Aristóteles dizia do ser humano: um ser essencialmente político (zoon politikon).

Mas qual a neutralidade dos autores que fundamentam suas teses? Unicamente porque são autores que defendem que é possível um conhecimento neutro, despido de valores e, portanto, de ideologia? Mas que neutralidade seria esta se é justamente os autores que afirmam ser o capitalismo uma sociedade do tipo natural, ou que corresponde à natureza humana e, portanto, postulam a manutenção das relações sociais que produzem a desigualdade e a exploração. Mas isso nada tem a ver com ideologia e política!

Por fim, o fundamentalismo religioso, ao utilizar-se do criacionismo para oporse ao que denomina de ideologia de gênero e entender que o homossexualismo e o lesbianismo são uma doença, manipula os pais e a sociedade, afirmando que determinados professores e conteúdos nas escolas estão induzindo as crianças a se tornarem homossexuais ou lésbicas.

Em torno dessa manipulação, criaram a expressão "Kit gay", acusando o governo e profissionais que estariam distribuindo materiais que incentivam 0 homossexualismo. Uma grosseira e criminosa inversão daquilo que é a orientação da Organização dos Direitos Humanos, que condena qualquer descriminação de 
gênero e opção sexual. A solicitação foi para que em todos os países se elaborassem materiais de orientação nas escolas de não descriminação de gênero e orientação sexual. Esta indicação era resultado de uma pesquisa elaborada em 2011 pelo Alto Comissariado das Nações Unidas (ACNUDH), na qual se evidenciou alarmante incidência de violência e discriminação em função de sua orientação sexual e identidade de gênero. A partir desta constatação, órgãos das Nações Unidas passaram a elaborar orientações contra a homofobia, feminicídio e descriminação por opção sexual20.

A junção de ultraconservadorismo econômico-social, da ideologia "Escola sem Partido, do fundamentalismo religioso e a disseminação do ódio contra adversários políticos, diversidade de gênero e orientação sexual e a falsificação de notícias constituíram o horizonte das forças sociais de extrema direita que governarão o país nos próximos quatro anos. Com a cultura extremada do autoritarismo, estas forças sinalizam um crescimento de traços de fascismo societário.

Os traços deste fascismo expressam-se mediante: a crescente investida ultraconservadora no campo econômico e social com o desmanche da esfera pública da educação, saúde, trabalho e, como tal, dos direitos universais; as investidas do partido ideológico "Escola sem Partido" contra a liberdade de expressão e de análise por parte dos professores sobre os temas científicos, filosóficos e culturais etc., com a incitação ao ódio e à delação por parte de pais e alunos, censura de autores e afirmação da pedagogia do medo; e, por fim, o fundamentalismo religioso que "adora bezerros de ouro" e que retroage à Idade Média querendo impor o criacionismo (interpretação metafísica) à ciência. A tese de que nascemos "homem e mulher" pode estar correspondendo à tese de que vivíamos num sistema geocêntrico e não o que a ciência demonstrou, heliocêntrico. Quando isto foi comprovado, a inquisição tinha torturado e mandado à fogueira seres humanos, assim como o regime fascista perseguiu os estrangeiros, ciganos e levou ao holocausto milhões de judeus.

Não existe verdade científica acabada. Tanto as ciências sociais e humanas quanto as ciências da natureza, da qual o ser humano é parte, são ciências

\footnotetext{
${ }^{20} \mathrm{https}: / /$ nacoesunidas.org/onu-apresenta-recomendacoes-sobre-a-protecao-dos-direitos-de-lgbt/ Acesso em 11 /11/2018. Ver também recomendações da UNESCO. Disponível em: https://www.terra.com.br/noticias/educacao/unesco-e-dever-do-mec-criar-politica-contra-homofobiana-escola,214a42ba7d2da310VgnCLD200000bbcceb. Acesso em: 20. Jan.2019.
} 
históricas. Se existe diferentes identidades de gênero e de orientação sexual, no plano das ciências, é algo que tem que ser compreendido biológica, histórica e culturalmente e não pelo dogma metafísico. Como explicita, de forma clara, Jaime Breilh ao analisar o que determina a saúde e o que determina a vida:

Cuando pensamos sobre la dicha determinación social de la salud, si queremos cuidar uma perspectiva dialética que no recaiga ni en el determinismo biológico ni en el determinismo histórico, tenemos que trabajar las relacionas "social-biológico" y "sociedad-naturaleza", de tal manera que ninguna de las partes pierda su presencia en la determinación. (BREILH, 2010, p.110).

Cabe à sociedade brasileira em suas instituições científicas, jurídicas, culturais, políticas, sindicais e movimentos sociais e populares criar mecanismos, não para barrar, mas para reverter o que não é apenas ameaça, mas uma realidade no tecido cultural e social em nossa sociedade. Reverter o conjunto de contrarreformas que aniquilam a esfera pública e, com ela, todos os direitos universais. Reverter a ideologia do ódio e pedagogia do medo dos ideólogos do partido da "Escola sem Partido" e, sobretudo, combater e buscar formas de impedir o avanço dos vendilhões dos templos e a subordinação da ciência ao credo de fanáticos do fundamentalismo religioso. Mais que nunca, colocar barreiras à junção de fundamentalismo econômico, fundamentalismo de extrema direita e fundamentalismo religioso, a esfinge que se coloca como mandato de "deus".

A estupidez humana, no sentido que sugerem Luciano Gallino e Albert Einstein, encontra em nossa sociedade atualmente o seu grau extremo, por ter sua força instalada no coração das instituições parlamentares, jurídicas e de gestão do Estado. Tratemos de nos defender pela unidade profunda, substancial e inabalável das forças sociais que querem que haja futuro visível.

\section{Referências:}

ALGEBAILE, Eveline. Escola pública e pobreza no Brasil: a ampliação para menos. Rio de Janeiro: Lamparina, 2009.

ALTVATER, Elmar. O fim do capitalismo como o conhecemos. Rio de Janeiro: Civilização Brasileira, 2010. 
BENJAMIN, Walter. In: LÖWY, Michael, "A contrapelo". A concepção dialética da cultura nas teses de Walter Benjamin (1940). Revista Lutas Sociais, São Paulo, n.25-26, p. 20-28, 2o sem. de 2010.

BRAY, Mark. Cinco lições para antifascistas. Disponível em: https://revistaserrote.com.br/2018/03/cinco-licoes-de-historia-para-antifascistas-por-markbray. Acesso em: 20 out. 2018.

BREILH, Jame. Las três "S" de la determinación de la vida: 10 tesis hacia uma visio crític de la determinación social de la vida y la salud. In: NOGUEIRA, Roberto Passos (Org.). Determinação social da saúde e reforma sanitária. Rio de Janeiro, CEBES, 2010, p. 87125.

CUNHA, Luiz Antonio. O ensino de ofícios artesanais e manufatureiros no Brasil escravocrata. São Paulo, Editora da Unesp; Brasília. DF, Flacso, 2000.

O ensino profissional na irradiação do industrialismo. $2^{\mathrm{a}} \mathrm{ed}$. São Paulo, Editora da Unesp; Brasília, DF, Flacso, 2005.

DA SILVA, Juremir Machado. Raízes do conservadorismo brasileiro. A abolição na imprensa e no imaginário social. Rio de Janeiro, Civilização Brasileira, 2018.

DESTUTT de TRACY, Antoine. Èlementes d'ideologie. Paris: Coutecier Imprimeurs Librarie.

FERNANDES, Florestan. A revolução burguesa no Brasil: ensaio de interpretação sociológica. Rio de Janeiro: Zahar, 1974.

Circuito fechado. São Paulo: Hucitec, 1977.

Rio de Janeiro: Zahar, 1975.

Capitalismo dependente e classes sociais na América Latina.

FRIGOTTO, Gaudêncio. Educação e crise do capitalismo real. $6^{a}$ ed. São Paulo: Cortez, 2015.

A produtividade da escola improdutiva. São Paulo: Cortez, 1984.

(Org.). Escola "sem" partido - esfinge que ameaça a educação e a sociedade brasileira. Rio de Janeiro: Editora LPP/UERJ, 2017.

GALLINO, Luciano. II denaro, il debito e la doppia crisi spiegati ai nostri nipoti. Torino, Edizione Einaudi, 2015.

HARVEY, David. O enigma do capital e as crises do capitalismo. São Paulo: Boitempo, 2011.

17 contradições do capitalismo. São Paulo: Boitempo, 2018.

HOBSBAWM. Eric. A era dos extremos. O curto século XX (1914-1991). São Paulo:

Schwarcz, 1995.

O novo século. São Paulo: Companhia das Letras, 2000. 
18 de abril de 2010. p. 4-6.

HUNT, E. K; SHERMAN, H. J. História do pensamento econômico. Petrópolis: Vozes, 1987.

JAMESON, Fredric. Pós-modernismo. A lógica cultural do capitalismo tardio. São

Paulo: Ática, 1996.

KOSIK, Karel. Dialética do concreto. Rio de Janeiro: Paz e Terra, 1986.

LINHART, Danièle. A desmedida do capital. São Paulo: Boitempo, 2007.

LOSURDO, Domenico. Contra-história do liberalismo. São Paulo: Ideias e Letras, 2009.

LÖWY, Michael. As aventuras de Karl Marx contra o Barão de Münchhausen marxismo e positivismo na sociologia do conhecimento. São Paulo: Cortez, 2013.

MANDEL, Ernest. O capitalismo tardio. México: Edições Era, 1972.

MALTHUS, Thomas Robert. Essay on the Principle of Population. Vol. 2. Nova York, 1961, p. 179-80. In: HUNT \& SHERMAN. História do pensamento econômico. Rio de Janeiro: Vozes, 1987.

MARX, Karl; ENGELS, Friedrich. A sagrada família. São Paulo: Boitempo, 2003.

MÉSZÁROS, István. A crise estrutural do capital. São Paulo: Boitempo, 2016.

MELLO, João Manuel C. O capitalismo tardio. São Paulo: Ed. Unesp, 2009.

PENNA, Fernando; QUEIROS, Felipe; FRIGOTTO, Gaudêncio (Orgs.). Escola democrática - antídoto ao Escola sem Partido. Rio de Janeiro, Editora LPP/UERJ, 2018.

PIKETTY, Thomas. O capital do século XXI. Rio de Janeiro: Intrínseca, 2014.

SCHULTZ, Theodore. O valor econômico da educação. Rio de Janeiro: Zahar, 1967.

Janeiro: Zahar, 1973.

O capital humano: investimentos em educação e pesquisa. Rio de

WILLIAMS, Raymond. Palavras-chave - um vocabulário de cultura e sociedade. São Paulo: Boitempo, 2007.

Recebido em: 08 de janeiro de 2019. Aceito em: 30 de janeiro de 2019. Publicado em: 28 de maio de 2019. 